\title{
Flower-like NiFe Oxide Nanosheets on Ni Foam as Efficient Bifunctional Electrocatalysts for the Overall Water Splitting
}

\author{
Bo Li, Qin Feng, Feng Jiang, Lizhi Peng, Tianfu Liu* \\ School of Chemistry and Chemical Engineering, Beijing Institute of Technology, Beijing, 100081, P. \\ R. China \\ *E-mail: liutf@bit.edu.cn
}

doi: $10.20964 / 2019.05 .24$

Received: 8 December 2018 / Accepted: 11 February 2019 / Published: 10 April 2019

\begin{abstract}
Since the oxygen evolution reaction (OER) is a fundamental step in the overall water splitting process, it is necessary for an ideal catalyst to require a small amount of energy to overcome the energy barrier at the electrode-electrolyte interface. Therefore, developing highly active and integrated catalysts is of great significance. Herein, we present a facile and viable method to fabricate flower-like NiFe oxide nanosheets electrocatalysts that are directly grown on nickel foam substrates through a hydrothermal reaction. By tuning the $\mathrm{Ni}$ :Fe ratio, the as-synthesized $\mathrm{NiFe}$ oxide exhibits excellent catalytic activity that surpasses the activity of the $\mathrm{RuO}_{2}$ benchmark catalyst, when tested as an electrocatalyst for the overall water splitting reaction. More importantly, the optimized $\mathrm{NiFe}$ oxide electrode possesses excellent OER activity in $1 \mathrm{M} \mathrm{KOH}$ with small overpotentials of 255 and $280 \mathrm{mV}$ at 10 and $50 \mathrm{~mA} \mathrm{~cm}^{-}$ ${ }^{2}$, respectively. When employed as a stable bifunctional catalyst to split water, this electrode achieved a current density of $10 \mathrm{~mA} \mathrm{~cm}$ at a cell voltage of $1.59 \mathrm{~V}$. This work presents a highly promising candidate for use as an electrode material and represents promising progress in its practical utilization and comprehensive industrialization.
\end{abstract}

Keywords: NiFe oxide; oxygen evolution reaction; bifunctional catalyst; electrocatalysts

\section{$\underline{\text { FULL TEXT }}$}

(C) 2019 The Authors. Published by ESG (www.electrochemsci.org). This article is an open access article distributed under the terms and conditions of the Creative Commons Attribution license (http://creativecommons.org/licenses/by/4.0/). 